\title{
Potenzial vorhanden
}

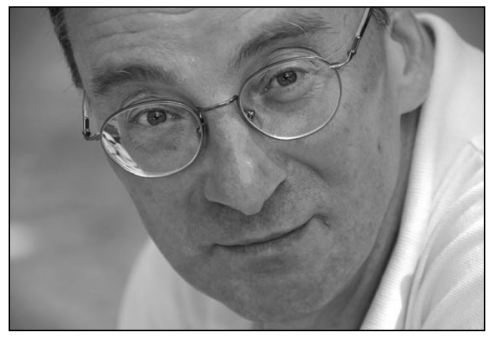

Foto: Petra Schmucker, Frankfurt am Main
Zwischen Flop und Paradigmenwechsel oszilliert die Einschätzung des Persönlichen Budgets nach fast einem Jahr endgültigen Inkrafttretens. Zwar wurde die neue Leistungsform bereits im Jahre 2001 gesetzlich eingeführt, zunächst jedoch auf Eis gelegt und dann in Bundesmodellprojekten erprobt. Seit dem 1. Januar 2008 kann aber jeder Leistungsberechtigte von seinem Sozialleistungsträger anstatt einer Sachleistung eine monatliche Geldsumme verlangen und damit seine Bedarfsdeckung selbst organisieren. Joachim Speicher hat vor zwei Jahren in dieser Zeitschrift plastisch beschrieben, welche Auswirkungen das im Pionierland des Persönlichen Budgets, in Rheinland-Pfalz, hatte: FitnessStudio statt Tagesförderstätte und Mallorca statt Wohnheim. * Mögen diese Fallbeispiele auch Ausnahmen sein, sie zeigen das Potenzial, das in dem Instrument des Persönlichen Budgets steckt. Und die Verantwortlichen sozialwirtschaftlicher Unternehmen sind gut beraten, diese Möglichkeiten bei ihren Zukunftsplanungen in Rechnung zu stellen. Die Wirkungen des Persönlichen Budgets können von größeren Erlösschwankungen - über die Michaela Weiß und Peter Weiß in ihrem Beitrag in diesem Heft berichten - bis zur Aushebelung von Entgeltvereinbarungen mit Leistungsträgern gehen, wenn diese plötzlich als »Budgetverwalter " ihrer Leistungsberechtigten auftreten. ** Dennoch, so Wolfgang Bayer von den v. Bodelschwinghschen Anstalten Bethel, befördere das Persönliche Budget in einer ganz besonderen Weise den paradigmatischen Wandel von der Fürsorge zur Dienstleistung, der von allen am Hilfeprozess Beteiligten langfristige Lern- und Veränderungsprozesse erfordere.

\section{Gerhard Pfannendörfer - Chefredaktion -}

* Joachim Speicher: Erfahrungen. Geld oder Liebe. In SOZIALwirtschaft 4/2006. Seite 10-13.

** Nach Feststellungen des Paritätischen Wohlfahrtsverbandes und seines Kompetenzzentrums (www.budget.paritaet.org) bezogen beispielsweise in Rheinland-Pfalz im Rahmen des Modellprojekts "Hilfe nach Maß « mehr als zwei Drittel der über 2.700 Leistungsempfänger diese Form des Persönlichen Budgets. Mit diesen anspruchsberechtigten Menschen wurde zwar ein Persönliches Budget vereinbart, die entsprechende Geldleistung erhalten die Betroffenen aber nicht. Auf der Grundlage einer »Abtretungserklärung « zahlt der Leistungsträger, etwa das örtliche Sozialamt, das Geld direkt an Privatpersonen, ambulante Dienste oder stationäre Einrichtungen als Leistungserbringer - ohne dabei an die Vereinbarungen nach \& 75 SGB XII gebunden zu sein.

\section{Demografischer Wandel}

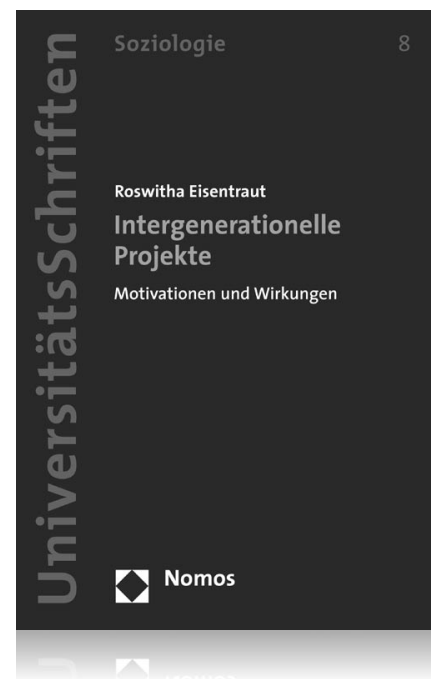

\footnotetext{
Intergenerationelle Projekte

Motivationen und Wirkungen

Von Roswitha Eisentraut

2007, 311 S., brosch., 56,-€,

ISBN 978-3-8329-2730-1

(Nomos Universitätsschriften -

Soziologie, Bd. 8)
}

Angesichts der aktuellen Debatte um demografische Entwicklung und Generationengerechtigkeit untersucht die Autorin intergenerationelle Begegnungen außerhalb von Familien.

Eine Gestaltungsmöglichkeit außerfamilialer Begegnungen zwischen den Generationen eröffnen „,inszenierte“ Projekte. Die Forschungsfragen der Arbeit richten sich auf das Spektrum möglicher Begegnungsorte und -inhalte, auf Motive für und Wirkungen von intergenerationeller Projektarbeit.

"Eine erste empirische Grundlage zur Erforschung intergenerationeller Projekte." Julia Franz, BildungsBlog, November 2007

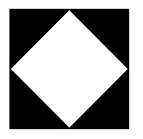

Nomos 